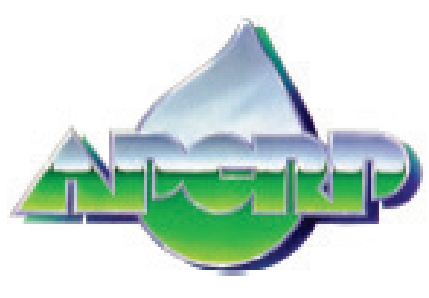

\title{
Evaluation of New Endothall and Florpyrauxifen-benzyl Use Patterns for Controlling Crested Floating Heart and Giant Salvinia
}

by Christopher R. Mudge and Michael D. Netherland

PURPOSE: The purpose of this research was to (1) evaluate concentration exposure time (CET) relationships for florpyrauxifen-benzyl (ProcellaCOR) for control of the floating leaved plant crested floating heart (Nymphoides cristata, $\mathrm{CFH}$ ) and (2) evaluate foliar applications of endothall (Aquathol $\mathrm{K}$ ) for control of $\mathrm{CFH}$ and the floating fern giant salvinia (Salvinia molesta).

BACKGROUND: The highly invasive floating leaved plant CFH continues to spread throughout Florida as well as South Carolina, Texas, North Carolina (Center for Invasive Species and Ecosystem Health 2010; Thayer and Pfingsten 2018), and recently into Louisiana (Winslow 2013). CFH is listed as a category 1 invasive species because it is an invasive exotic species that alters native plant communities by displacing native species, changing the community, or changing ecological structures (Florida Exotic Pest Plant Council 2017). In severe infestations, overlapping leaves form dense mats that interfere with boat traffic and recreational water uses (Willey 2014) and reduce light availability to submersed native vegetation and phytoplankton (Burks 2002a). To date, aquatic herbicides are the best option for managing CFH. Recently, several registered and experimental herbicides have been evaluated against CFH and with mixed efficacy (Willey 2012; Glomski, Willey, and Netherland 2014; Willey 2014; Beets and Netherland 2018).

Florpyrauxifen-benzyl. The new auxin mimic aquatic herbicide florpyrauxifen-benzyl represents a new mode of action (arylpicolinate) that will be used to control invasive submersed, floating, and emergent species in US Army Corps of Engineers reservoirs and other waterbodies throughout the United States. This herbicide was registered in 2018 (University of Florida 2018). Growth chamber research by Netherland and Richardson (2016) evaluated florpyrauxifen-benzyl (SX-1552 [ester] and SX-1552A [acid] formulations) at in-water concentrations between 1 and $81 \mathrm{ppb}^{1}$ as a 14-day static exposure against sprouting $\mathrm{CFH}$ ramets. Results indicated that effective concentration required to reduce $50 \%$ of the test population (EC50) values of 5.6 and $23.9 \mathrm{ppb}$, respectively, were determined for SX-1552 and SX-1552A. In 2016, two mesocosm trials using more mature plants collected from field sites demonstrated that florpyrauxifen-benzyl must be applied at concentrations $\geq 24 \mathrm{ppb}$ and plants exposed for $\geq 24 \mathrm{~h}$ (Mudge, unpublished data) to provide $90-99 \%$ control. The plants evaluated in the mesocosm trials were mature and surface matted when florpyrauxifen-benzyl was applied in July or August. The shorter exposure times, plant maturity, or timing of herbicide

1. For a full list of the spelled-out forms of the units of measure used in this document, please refer to US Government Publishing Office Style Manual, 31st ed. (Washington, DC: US Government Publishing Office, 2016), 248-52, https://www.govinfo.gov/content/pkg/GPO-STYLEMANUAL-2016/pdf/GPO-STYLEMANUAL-2016.pdf. 
application may have influenced efficacy. Additional research will determine if treating earlier in the growing season or extending exposure times will achieve complete control.

To better combat $\mathrm{CFH}$ and develop new tools for managing this highly invasive species, mesocosm research was conducted to determine whether treatment timing and longer exposure periods of florpyrauxifen-benzyl will control CFH. Prior mesocosm work with the auxin mimic herbicides 2,4$\mathrm{D}$ and triclopyr essentially showed no activity on $\mathrm{CFH}$ at concentration as high as 2-4 ppm (Willey et al. 2014).

Endothall. In contrast to florpyrauxifen-benzyl, endothall has been registered for aquatic use for over 58 years. In August 2016, Santee Cooper aerially applied liquid endothall (dipotassium salt) with no water carrier (that is, 0 US gallons per acre [GPA], no diluent) to the foliage of 153 ha (one plot was 79 ha and the other 74 ha) of surface-matted CFH in Lake Marion, South Carolina. The product was applied without water or adjuvant to eliminate the excess weight from the water carrier (or additive). This application sought to achieve an herbicide concentration of $4 \mathrm{ppm}$ throughout the water column to control parent plants and ramets (daughter plants). Within hours following the application, surface leaf browning was noted. Water sampling and subsequent efficacy surveys supported by the US Army Engineer Research and Development Center (ERDC) and the University of Florida determined this application method was highly successful and controlled the CFH in the application area. The only healthy material observed nine months after treatment (MAT) were ramets along the edge of the treatment area. While this is not a new use pattern for operational control of submersed aquatic plants, it was the first time that undiluted product was applied to floating leaf plants at a large scale. Endothall has been applied aerially with no water carrier to manage large hydrilla infestations in the Kissimmee Chain of central Florida for several years (M. Netherland, pers. comm. 2017).

Although the application of endothall to $\mathrm{CFH}$ in Lake Marion was highly efficacious, the speed of control suggests a mechanism of control not fully understood or ever tested. Prior research demonstrated concentrations of 3-4 ppm endothall for $48 \mathrm{~h}$ exposures failed to control CFH when applied as a subsurface treatment (Willey et al 2014). Static exposures provided control of CFH; however, it took two to three weeks to observe severe leaf injury. While there is some new evidence that endothall has systemic properties, we feel that concentrating the herbicide in the upper water column for a very short period of time initially "burned" the floating leaves. We speculated that without a leaf attached, the petioles were vulnerable to decay due to their inability to regenerate new leaves because of nonmeristematic tissue. The ramets were likely controlled by the extended exposure to endothall in the water column.

In July 2017, Santee Cooper personnel discovered the highly invasive floating fern giant salvinia in upper Lake Marion. The introduction of giant salvinia has altered current management plans (L. McCord, pers. comm. 2017), particularly in areas where giant salvinia and CFH coexist, since each species currently requires different management plans and treatments. The goal is to eradicate giant salvinia, if possible, since this plant has caused widespread issues in Louisiana and Texas (Mudge, Perret, and Winslow 2016). Endothall is efficacious against giant salvinia when applied to the foliage with a water carrier at 100 or 200 GPA and surfactant (Nelson, Skogerboe, and Getsinger 2001; Nelson, Glomski, and Gladwin 2007); however, it is unknown whether endothall applied without water or in a low-volume water carrier could improve control. 
Mesocosm research evaluated foliar use of endothall with several different water carrier volumes. While traditional volumes of 50-100 gallons of carrier are used in aquatic weed management against $\mathrm{CFH}$, giant salvinia, and other emergent plants, results from the field suggest that using lower carrier volumes could potentially enhance control of floating leaf or floating plants.

\section{MATERIALS AND METHODS:}

Florpyrauxifen-benzyl concentration exposure time (CET) vs crested floating heart (CFH). The florpyrauxifen-benzyl CET vs. CFH mesocosm trial was conducted at the Louisiana State University (LSU) AgCenter Aquaculture Research Facility in Baton Rouge, Louisiana. On 2 May 2017, mature, rooted crested floating heart plants (ca. $0.9 \mathrm{~m}$ in length) were collected from a local pond near the campus of LSU. One healthy plant was placed into a $3 \mathrm{~L}$ pot filled with Black Kow topsoil and Osmocote fertilizer $\left(2 \mathrm{~g} \mathrm{~L}^{-1}\right)$ and then placed inside $1136 \mathrm{~L}$ Rubbermaid livestock tanks. The containers were filled with pond water $(\mathrm{pH} 8.5)$ and amended with peat moss $(500 \mathrm{~g})$ to lower the $\mathrm{pH}$ to $<7.0$. In addition, Miracle-Gro fertilizer $\left(16 \mathrm{mg} \mathrm{L}^{-1}, 24-8-16\right)$ was added to the experimental units prior to herbicide application and as needed to support plant growth. Water level was maintained weekly at $200 \mathrm{~L}$ ( $45.7 \mathrm{~cm}$ height). All plants were allowed to acclimate to container conditions for two weeks prior to herbicide application (figure 1). On 16 May 2017, florpyrauxifenbenzyl (ProcellaCOR SC, SePRO, Carmel, Indiana) was applied subsurface at 12, 24, and $36 \mathrm{ppb}$ to $\mathrm{CFH}$, and plants were exposed for one, three, and seven days, as well as static exposures (eight weeks). At the conclusion of each exposure period, the tanks were drained and refilled three times to remove herbicide residue. Treatments were randomly assigned and replicated four times. At eight weeks after treatment (WAT), all viable biomass above the sediment surface was harvested, dried to a constant weight $\left(65^{\circ} \mathrm{C}\right)$, and recorded as dry-weight biomass. Data were subjected to analysis of variance (ANOVA) and means separated using Fisher's Protected LSD $(p \leq 0.05)$.

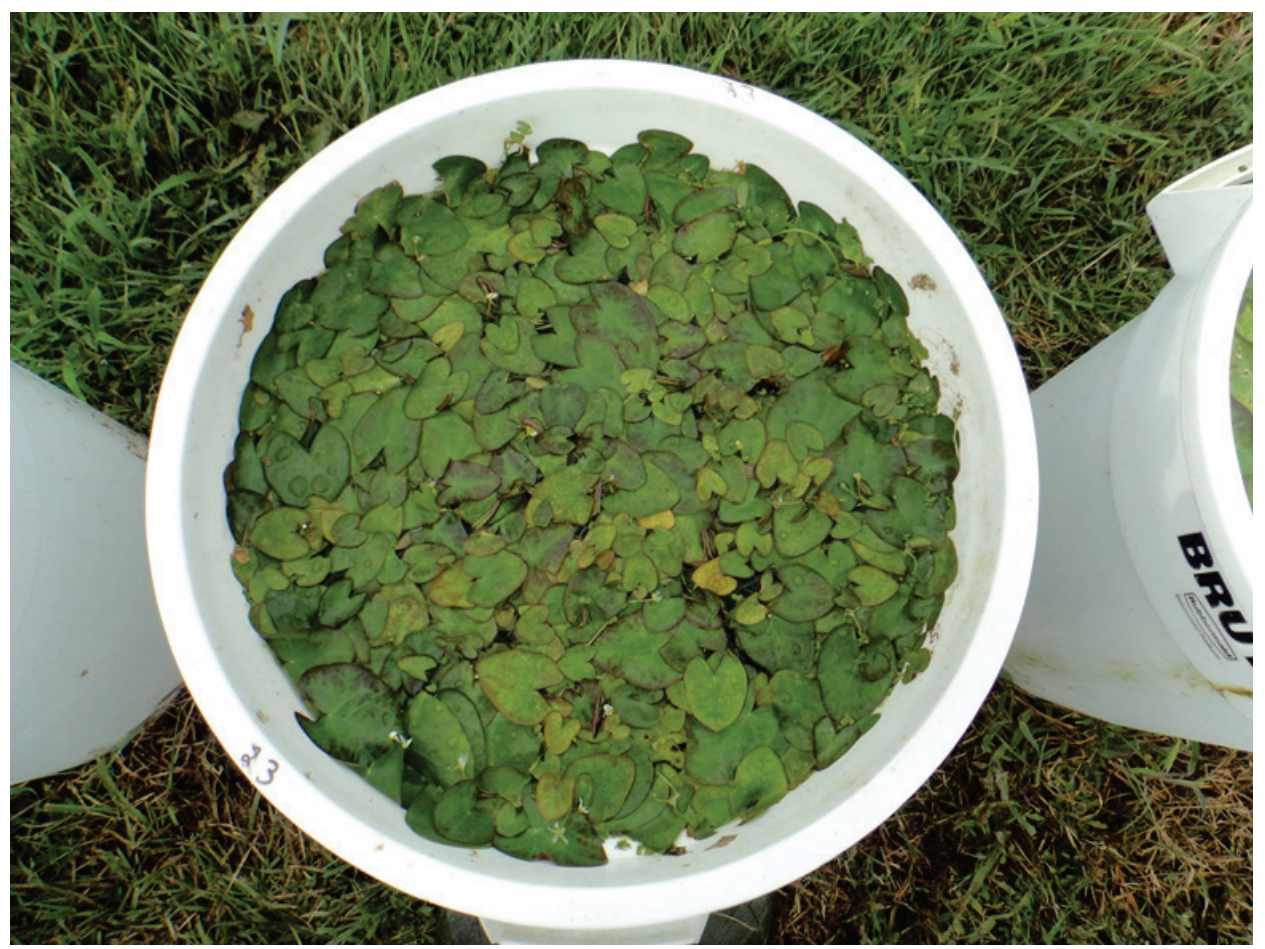

Figure 1. Crested floating heart cultured in $76 \mathrm{~L}$ containers prior to herbicide application. 
Endothall Foliar at Low Carrier Volume vs CFH. The endothall foliar trial was conducted in August 2017 at LSU Aquaculture to evaluate low-volume water carrier applications against CFH. The planting methods were identical to the florpyrauxifen-benzyl trial, except potted plants were placed inside $76 \mathrm{~L}$ plastic containers $(49.5 \mathrm{~cm}$ diameter by $58.4 \mathrm{~cm}$ height $)$ amended with the same concentration of fertilizer and $30 \mathrm{~g}$ of peat moss. After a two-week acclimation period, CFH was treated with endothall on 9 August 2017. The target in-water concentration for all treatments was 3 ppm but was delivered via foliar application. Endothall (Aquathol K, UPL NA, King of Prussia, Pennsylvania) was applied to the foliage of $\mathrm{CFH}$ using a forced-air $\mathrm{CO}^{2}$-powered sprayer at an equivalent of $0,1,3,5,10,25,50$, or $100 \mathrm{GPA}\left(0,9,28,47,93,234,467\right.$, or $\left.935 \mathrm{~L} \mathrm{ha}^{-1}\right)$ diluent delivered through a single TeeJet $80-0067$ nozzle at $8 \mathrm{psi}^{2}{ }^{2}$ The higher carrier volume treatments $(25$, 50 , and $100 \mathrm{GPA}$ ) represent an application from a boat or ground rig, whereas $\leq 10 \mathrm{GPA}$ is commonly applied via helicopter or fixed-wing aircraft. In addition, endothall was applied as a subsurface injection at $3 \mathrm{ppm}$ for $24 \mathrm{~h}$ or static exposures. Regardless of application method or carrier volume, $3.5 \mathrm{~mL}(0.12 \mathrm{oz})$ per tank was applied to the foliage of the plants or subsurface. At $24 \mathrm{~h}$ after treatment (HAT), all foliar treated plants were removed from the treated containers and placed in new containers with herbicide-free pond water and fertilizer. Treatments were randomly assigned and replicated three times. At 5 WAT, all viable biomass above the sediment surface was harvested, dried, weighed, and subjected to the same statistical procedures as the previous trial.

Endothall Foliar at Low Carrier Volume vs Giant Salvinia. The endothall foliar vs. giant salvinia trial was conducted at LSU Aquaculture in August 2017. Giant salvinia used in this research was collected from cultures maintained at LSU Aquaculture. On 21 August 2017, equal amounts of fresh plant material, enough to cover ca. $50 \%$ of the water surface, were placed inside $76 \mathrm{~L}$ plastic containers. The containers were filled with pond water that was amended with MiracleGro $\left(41.6 \mathrm{mg} \mathrm{L}^{-1}\right)$ and peat moss $(30 \mathrm{~g})$. Water level was maintained weekly at $60 \mathrm{~L}$. Culture techniques were adapted from previous giant salvinia research (Nelson, Skogerboe, and Getsinger 2001; Nelson Glomski, and Gladwin 2007; Mudge et al. 2012). Similar to the endothall vs. CFH trial, endothall was applied to the foliage of giant salvinia with $0,1,3,5$, or 100 GPA diluent on 24 August 2017 ( 3 days after planting). In addition, endothall was applied as a subsurface injection at $3 \mathrm{ppm}$ for a static exposure. At the time of herbicide application, plants covered ca. $75 \%$ of the water surface. All plants remained in the original containers throughout the trial and were not moved to herbicide-free water. Treatments were randomly assigned and replicated three times. At 5 WAT, all viable biomass was harvested, dried, weighed, and subjected to the same statistical procedures as the previous trials.

\section{RESULTS AND DISCUSSION:}

Subsurface Florpyrauxifen-benzyl CET vs CFH. All subsurface florpyrauxifen-benzyl treatments resulted in injury to CFH one day after treatment (DAT). Similar to previous research (Netherland and Richardson 2016), CFH stems were elongated and produced epinastic bending of the petioles (Richardson, Haug, Netherland 2016), which is common among plants exposed to auxin mimic herbicides (Shaner 2014). Several of the plants died within the first 2-3 WAT, and those plants that recovered by the conclusion of the trial ( 8 WAT), were small in size or free-

2. For a full list of the spelled-out forms of the chemical elements used in this document, please refer to $U S$ Government Publishing Office Style Manual, 31st ed. (Washington, DC: US Government Publishing Office, 2016), 265, https://www.govinfo.gov/content/pkg/GPO-STYLEMANUAL-2016/pdf/GPO-STYLEMANUAL-2016.pdf. 
floating ramets. With one exception, all subsurface applications of florpyrauxifen-benzyl, regardless of concentration or exposure time, resulted in $79-100 \%$ control 8 WAT (figure 2). The $12 \mathrm{ppb}$, one-day exposure only provided 53\% control. In general, as the exposure time increased from one day to static exposure for florpyrauxifen-benzyl at $12 \mathrm{ppb}$, biomass decreased. The 24 $\mathrm{ppb}$ treatments followed a similar trend except for the seven-day exposure. All $36 \mathrm{ppb}$ treatments resulted in $98-100 \%$ control. Florpyrauxifen-benzyl is primarily degraded by photolysis with minor degradation attributed to microbes and hydrolysis at $\mathrm{pH}>9$ (Heilman and Getsinger 2018; TRC Environmental 2017). The herbicide is expected to have an average aqueous half-life of one to eight days but will be highly dependent on environmental conditions (Heilman and Getsinger 2018; TRC Environmental 2017; Massachusetts Department of Agriculture 2019). The earlier treatment timing in May (compared to July or August 2016) resulted in improved control. The plants in the current research were mature but not surface matted at herbicide application. Future research should investigate the role of timing and plant phenology.

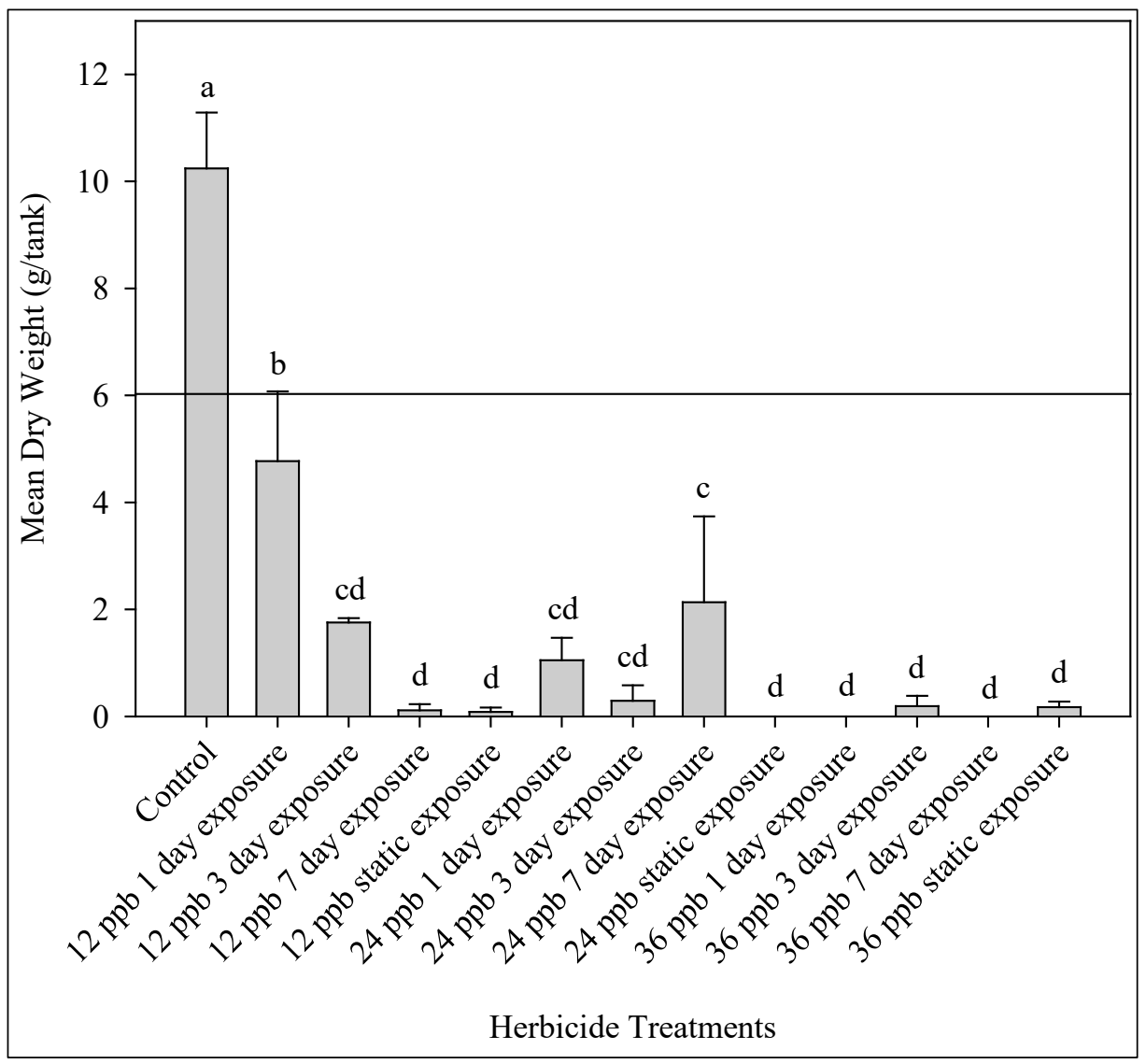

Figure 2. Mean ( \pm standard error) dry weight response of crested floating heart to 1,3 , and 7 day and static exposures of florpyrauxifen-benzyl at 12 , 24 , and $36 \mathrm{ppb}$. Means with the same letter are not significant according to Fisher's LSD $(p \leq 0.05)$. Horizontal line represents pretreatment biomass.

This work demonstrates that a subsurface use pattern for the florpyrauxifen-benzyl will be beneficial for managing CFH in a variety of settings where exposures may be limited to $\leq 1$ day. In larger treatment blocks or protected areas, extended exposure periods may improve control. These data provide information that suggests florpyrauxifen-benzyl is active on CFH at low 
concentrations and comparatively short exposure periods. This research also suggests that florpyrauxifen-benzyl has orders of magnitude greater activity on $\mathrm{CFH}$ when compared to other auxin mimic herbicides.

Endothall Foliar at Low Volume Water Carrier vs CFH. All foliar-applied endothall resulted in chlorosis of the leaves of CFH in less than 6 HAT (figure 3). As the water carrier volume decreased from 100 to 0 GPA, the intensity of injury symptoms increased during the first week of the trial. In addition, the lower water-carrier volumes ( $\leq 10 \mathrm{GPA})$ provided greater injury, whereas the 25-100 GPA treatments resulted in more green and healthy leaves due to more dilution and mixing into the water column. The lower GPA treatments were less diluted and provided rapid burn to the surface and secondary leaves. Whenever the plants were removed from the herbicide treated water at 24 HAT, leaves and petioles (stems) treated with 0,1 , and 3 GPA began to lose integrity (that is, necrotic leaf tissue and petioles) (figure 4). Despite the rapid desiccation to the leaves of parent plants and ramets (attached and free floating) following all treatments, plant recovery was observed in some treatments at two to six DAT. In particular, plants treated with 5100 GPA had new leaves and flowers at or above the water surface soon after leaves of the parent plants disintegrated (figure 5). If the carrier volume $\leq 3 \mathrm{GPA}$, the concentrated herbicide was able to rapidly burn through the leaves of the parent plants and ramets. The average number of petioles per plant (pot) for the control, $0,1,3,5,10,25,50$, or 100 GPA treatments were $61,0,0,0,1,52$, 54, 103, and 93, respectively, at 8 WAT (data not shown). Plants exposed to endothall subsurface for $24 \mathrm{~h}$ were slowly injured, but plants recovered in $<2 \mathrm{WAT}$. The static exposure treatments were more efficacious than the $24 \mathrm{~h}$ exposure treatment, but two of the three replicates recovered in circa 3 WAT. This suggests that the method of application was an important variable that resulted in significant differences in control and confirms earlier work that suggests subsurface applications of endothall do not provide acceptable control-especially when exposure periods are short (Willey et al 2014). 


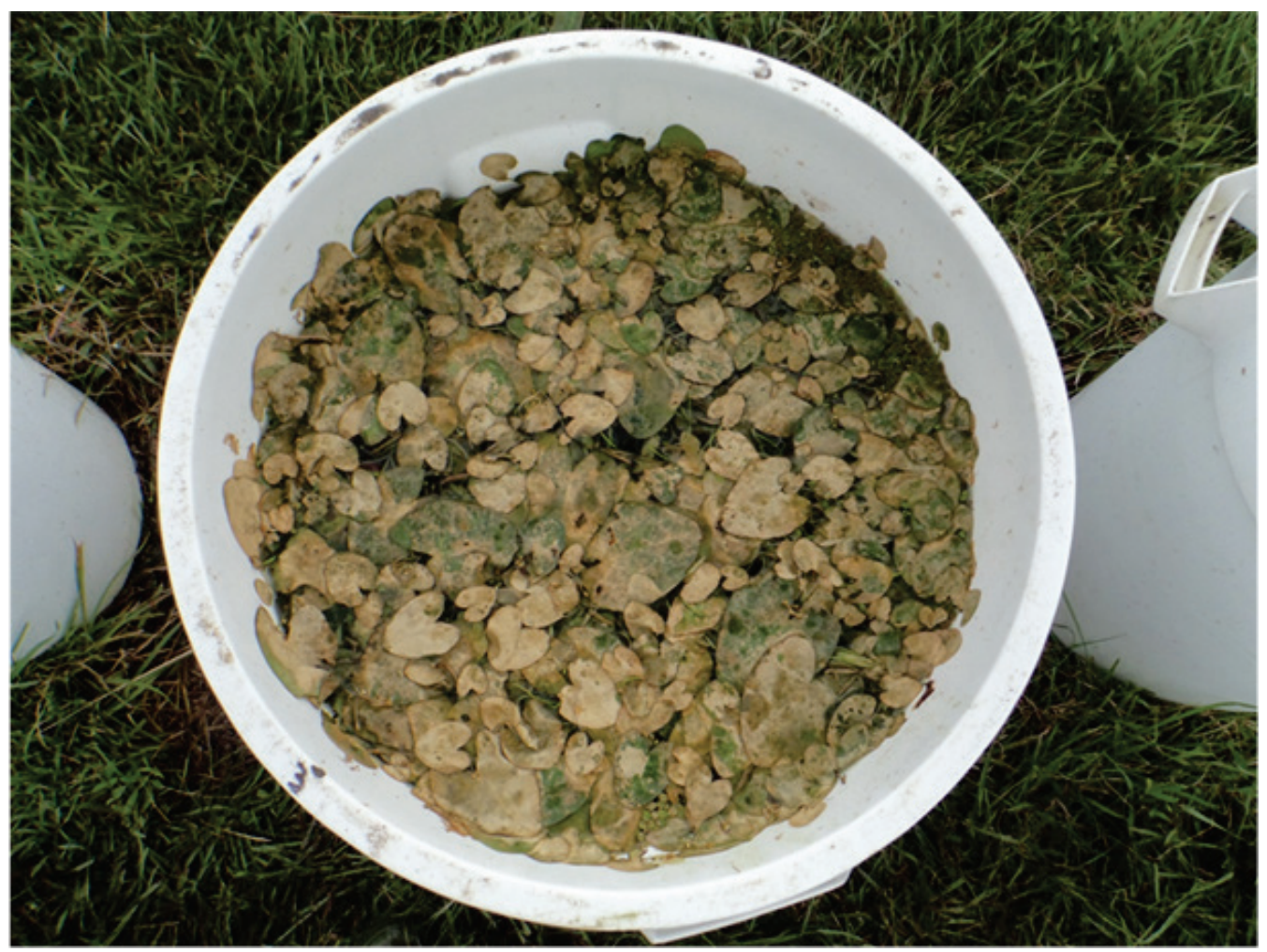

Figure 3. The effect of foliar applied endothall (dipotassium salt) with 0 gallons per acre (GPA) diluent on crested floating heart 1 day after treatment.

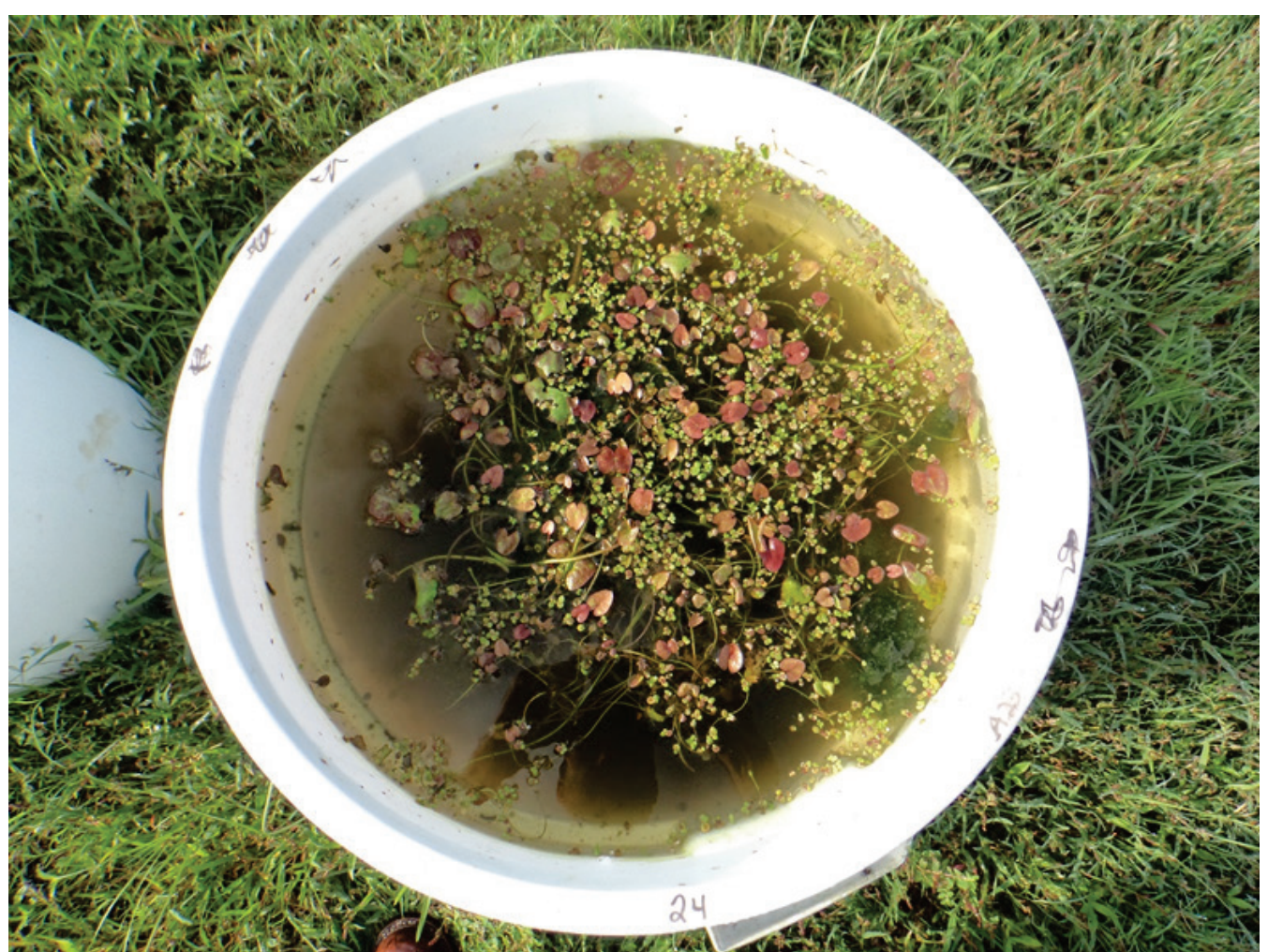

Figure 4. The effect of foliar applied endothall (dipotassium salt) with 10 GPA diluent on crested floating heart 6 days after treatment. 


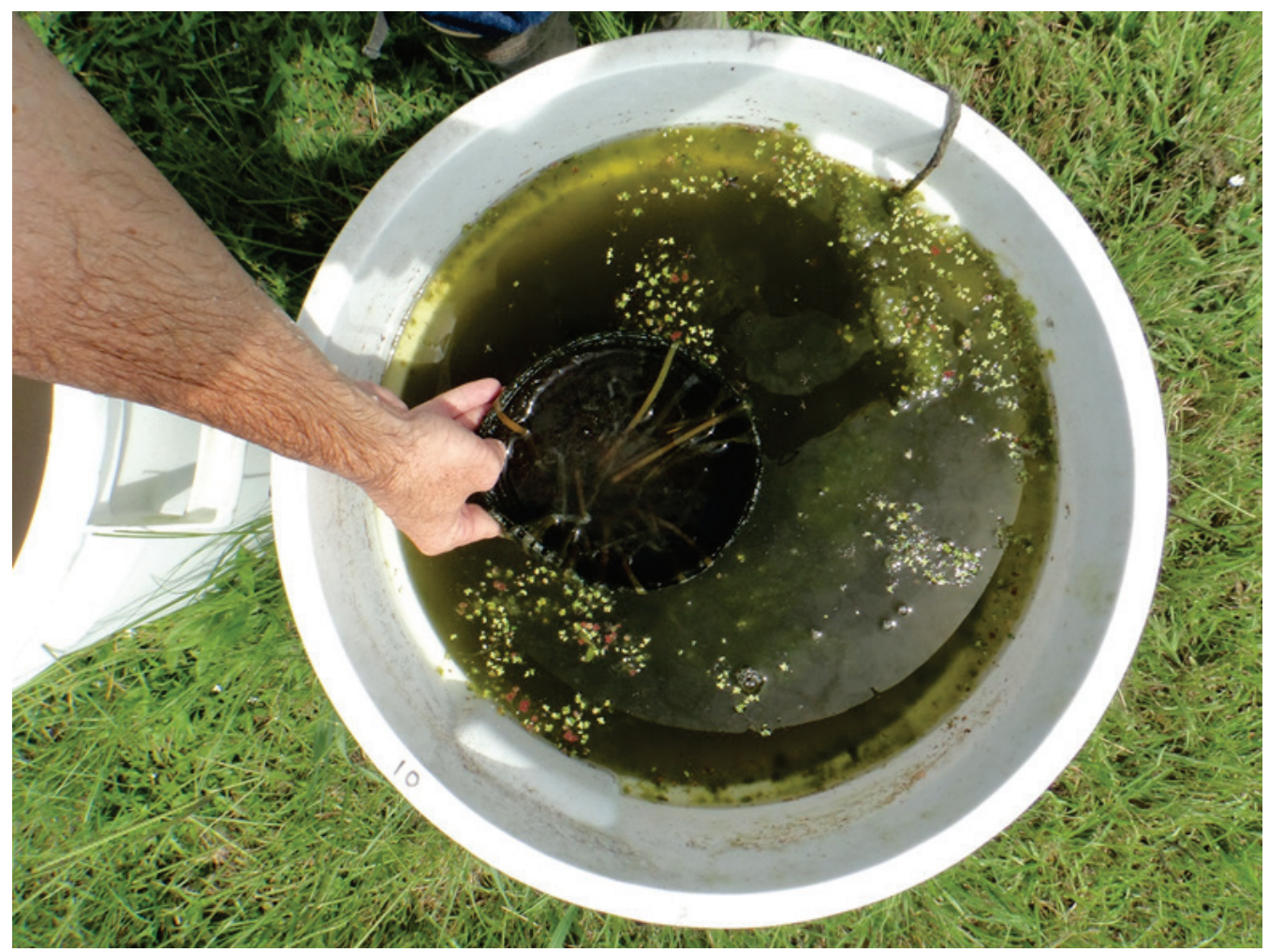

Figure 5. The effect of foliar applied endothall (dipotassium salt) with 3 GPA diluent on crested floating heart petioles 16 days after treatment.

All treatments, except endothall applied with 100 GPA diluent, reduced CFH dry weight 42-100\% of the nontreated control (figure 6). There were no differences in control $(99-100 \%)$ for plants exposed to foliar applications of endothall between 0 and 5 GPA. In particular, the 0 GPA treatment resulted in 100\% control and supports observations following operational efforts conducted by Santee Cooper in 2016. In this study, the 1, 3, and 5 GPA applications would also provide acceptable control if a diluent (water) was required to minimize equipment damage from the concentrated product. The 10-100 GPA treatments, as well as the subsurface $24 \mathrm{~h}$ exposure treatment, provided unacceptable control and would not be recommended for operational control of CFH. Although the subsurface static exposure provided $84 \%$ control of $\mathrm{CFH}$, plants recovered from the treatment, and an extended exposure in a field setting would likely not occur under natural conditions because of product degradation and dispersion from the application site.

In this research, endothall was applied as a foliar or subsurface treatment to mature, surface-matted plants. The low-volume, foliar application strategy would likely require that plants be surface matted in order to provide optimal efficacy. Despite the dense layer of plants (parent and daughter) at the water surface, 4 of the 10 treatments were highly efficacious and should be further investigated in a field setting using operational equipment. We speculate that the application method results in the concentrated herbicide providing rapid burn of the surface leaves prior to becoming diluted in the water column. Maintaining water column concentrations at target levels for a sufficient period of time likely results in control of ramets and root crowns. Rapid control of the surface canopy and long-term control of ramets is a highly desirable outcome when controlling $\mathrm{CFH}$. We would also recommend evaluating additional rates of endothall using this application method, as lower in-water concentrations may still provide control. 


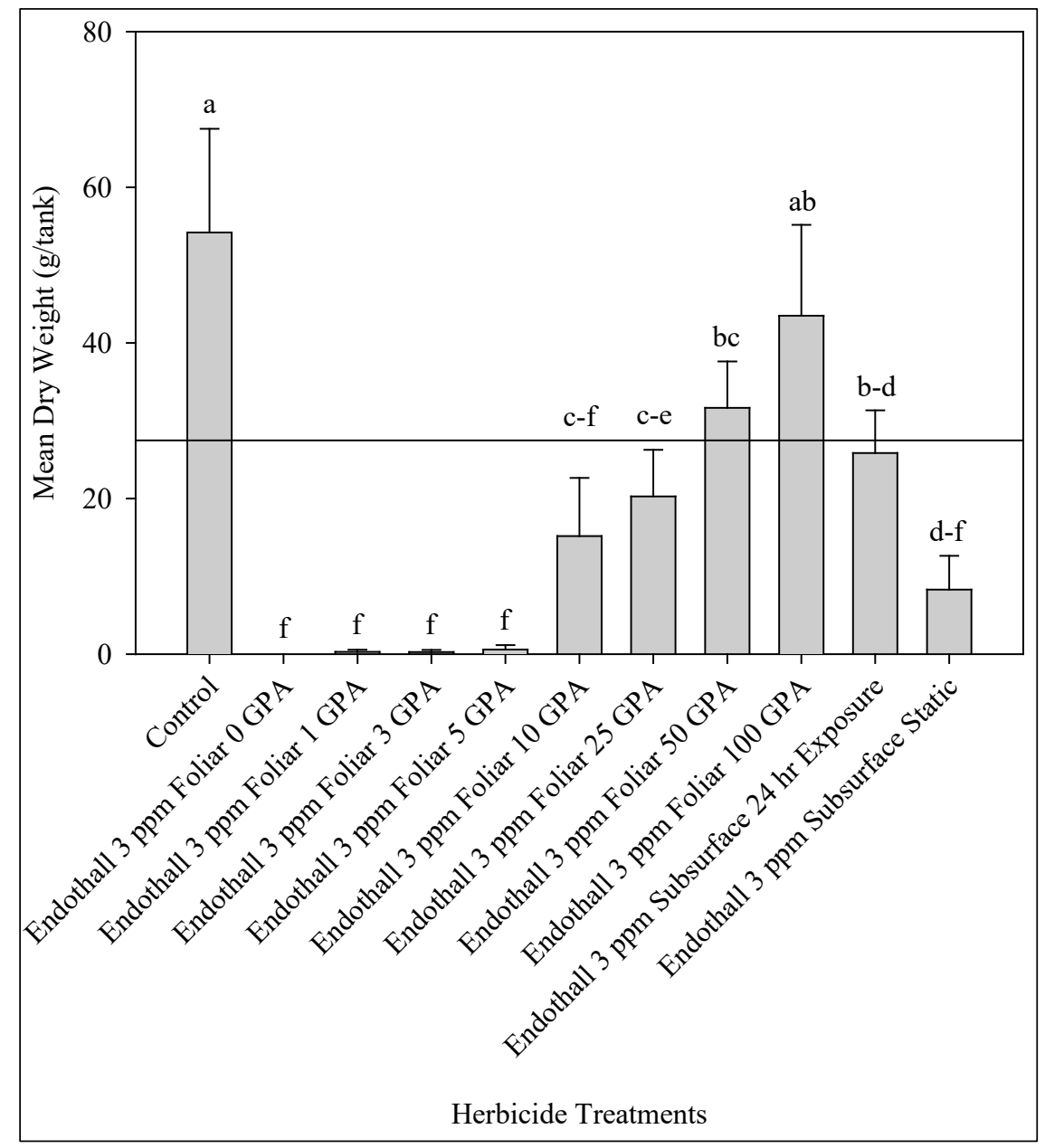

Figure 6. Mean ( \pm standard error) dry weight response of crested floating heart to foliar and subsurface applications of endothall (dipotassium salt) targeted to provide $3 \mathrm{ppm}$. Foliar treatments were applied at $0,1,3,5,10,25,50$, or 100 GPA diluent. All plants exposed to foliar applications were removed from the treated water 24 hours after treatment. Means with the same letter are not significant according to Fisher's LSD $(p \leq 0.05)$. Horizontal line represents pretreatment biomass.

Endothall Foliar at Low Carrier Volume vs Giant Salvinia. All foliar applied endothall treatments resulted in necrosis to giant salvinia fronds about two days after application. Due to substantial cloud cover from an impending hurricane in Texas, injury developed slowly throughout the first week of the trial but intensified around seven DAT (figure 7). Also, the surface of the floating fronds was covered by rows of white trichomes (that is, hairs) (McFarland et al. 2004), which are capable of repelling water and aiding floatation (Harper 1986). Since an adjuvant was not used with endothall, the trichomes likely reduced herbicide movement and uptake into the plant and slowed down herbicide injury. Future trials should incorporate adjuvants or surfactants into the spray solution to increase injury and speed of plant control. The water surface was not completely covered with plants (ca. $20-25 \%$ open water), and it is likely some of the spray solution entered the water column. Most floating plants are not impacted by aqueous endothall 
concentrations (1-5 ppm). None of the treatments provided complete control and plants were recovering by the conclusion of the experiment.

All endothall treatments, regardless of application technique or GPA, reduced giant salvinia biomass $32-95 \%$ of the nontreated control (figure 8). There were no differences in control (7895\%) among treatments applied at $\leq 5$ GPA. Although the $3 \mathrm{ppm}$ subsurface treatment reduced biomass, plants recovered prior to the conclusion of the trial, and this application method should be avoided. On the basis of the data collected in the endothall vs. giant salvinia and CFH trials, lower GPA applications should be used to improve plant control. The foliar use of this legacy herbicide should be field tested in Louisiana and Texas, where giant salvinia has been widespread for almost two decades. This nontraditional application method should also be evaluated in Santee Cooper to determine whether mixed populations of $\mathrm{CFH}$ and giant salvinia can be controlled.

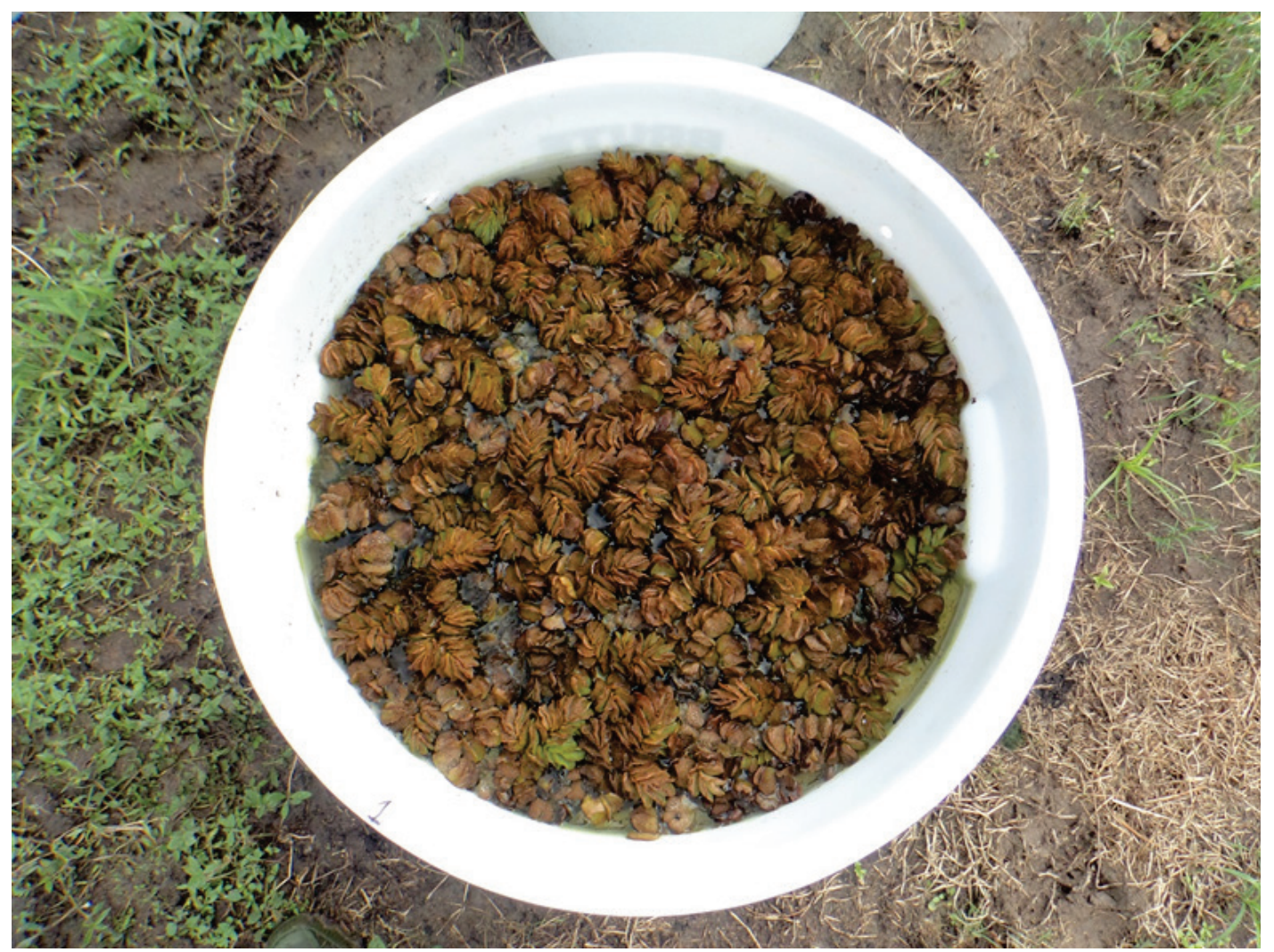

Figure 7. The effect of foliar applied endothall (dipotassium salt) with 0 GPA diluent on giant salvinia 7 days after treatment. 


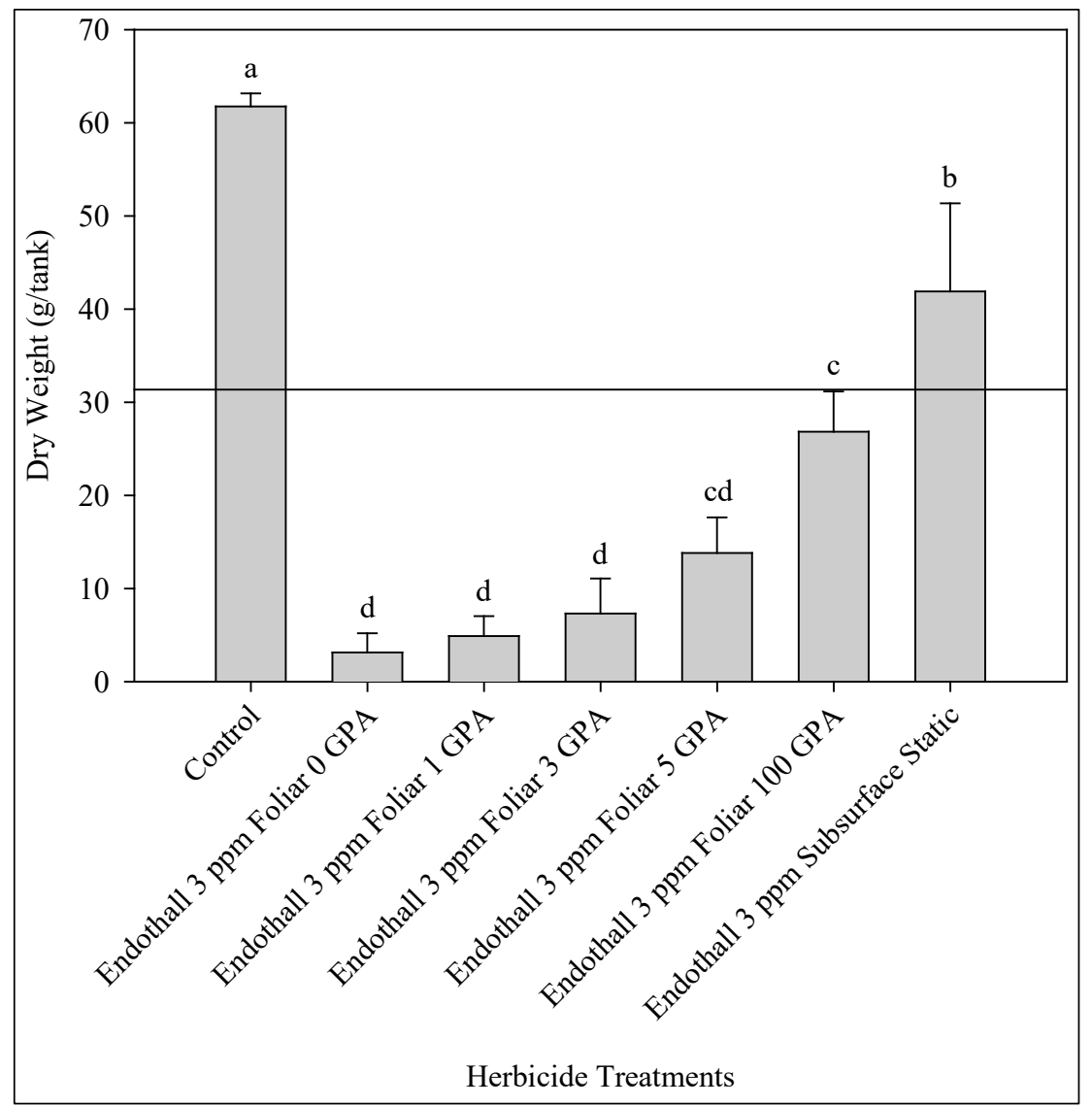

Figure 8. Mean ( \pm standard error) dry weight response of giant salvinia to foliar and subsurface applications of endothall (dipotassium salt) targeted to provide $3 \mathrm{ppm}$. Foliar treatments were applied at 0, 1, 3, 5, and 100 GPA diluent. Means with the same letter are not significant according to Fisher's LSD $(p \leq 0.05)$. Horizontal line represents pretreatment biomass.

FUTURE WORK: Field trials evaluating the efficacy of florpyrauxifen-benzyl as a subsurface treatment against CFH and endothall as a foliar application against $\mathrm{CFH}$ and giant salvinia should be investigated to verify the results of these mesocosm trials.

ACKNOWLEDGMENTS: Support for this project was provided by the Aquatic Plant Control Research Program (APCRP). The author would like to thank Dr. Bradley Sartain, Trista Galivan, and Nick Firmin for technical assistance throughout the research. Permission to publish this information was granted by the Chief of Engineers. Citation of trade names does not constitute an official endorsement or approval of the use of such products.

Portions of the results of this study were previously presented in "Exploring Alternative Giant Salvinia (Salvinia molesta D.S. Mitchell) Management Strategies” for the 58th Annual Meeting of the Aquatic Plant Management Society, Buffalo, NY, July 15-18, 2018. http://www.apms .org/wp/wp-content/uploads/1-2018-Final-Program-6-11-18.pdf. 
POINTS OF CONTACT: For additional information, contact Dr. Christopher R. Mudge (225) 578-1208, Christopher.R.Mudge@usace.army.mil, or the Acting Manager of the Aquatic Plant Control Research Program, Dr. Christine Vanzomeren (601) 634-3702,

Christine.M.Vanzomeren@usace.army.mil. This technical note should be cited as follows:

Mudge, Christopher R., and Michael D. Netherland. 2020. Evaluation of New Endothall and Florpyrauxifen-benzyl Use Patterns for Controlling Crested Floating Heart. APCRP Technical Notes Collection. ERDC/TN APCRP-CC-22. Vicksburg, MS: US Army Engineer Research and Development Center. https://el.erdc.dren.mil/aqua/aqua.html.

\section{REFERENCES}

Beets J, Netherland MD. 2018. Mesocosm response of crested floating heart, hydrilla, and two native emergent plants to florpyrauxifen benzyl. J. Aquat. Plant Manage 56:57-62.

Center for Invasive Species and Ecosystem Health. 2010. Crested floating heart, Nymphoides cristata (Roxb.) (Ktze.). www.invasive.org/browse/subinfo.cfm?sub=11616. Accessed September 29, 2020.

Florida Exotic Pest Plant Council. 2017. List of Invasive Plant Species http://www.fleppc.org/list/list.htm. Accessed September 29, 2020.

Glomski LM, Willey LN, Netherland MD. 2014. The efficacy of protox inhibiting herbicides alone and in combination with glyphosate to control crested floating heart. J. Aquatic Plant Manage. 52:9092.

Harper LM. 1986. Management plan: Salvinia molesta Mitchell. Unpublished report, Advisory Services Division, Ministry of Agriculture and Fisheries, Hamilton, New Zealand.

Heilman MA, Getsinger K. 2018. Early operational demonstration of selective invasive watermilfoil control with ProcellaCOR@. https://bugwoodcloud.org/mura/mipn/assets/File/UMISC2018/Wednesday/PM/Heilman Early\%20Operational\%20Demo. ProcellaCOR.pdf. Accessed September 29, 2020.

LSU AgCenter. 2017. Louisiana Agriclimatic Information System. http://weather.lsuagcenter.com. Accessed September 29, 2020.

Massachusetts Department of Agriculture. 2019. Review of florpyrauxifen-benzyl for application to Massachusetts lakes and ponds. https://www.mass.gov/doc/florpyrauxifen-benzyl/download. Accessed September 29, 2020.

McFarland DG, Nelson LS, Grodowitz MJ, Smart RM, Owens CS. 2004. Salvinia molesta D.S. Mitchell (Giant Salvinia) in the United States: A review of species ecology and approaches to management. ERDC/EL SR-04-2. Vicksburg, MS: US Army Engineer Research and Development Center.

Mudge CR, Heilman MA, Theel HJ, Getsinger KD. 2012. Impact of subsurface and foliar penoxsulam and fluridone applications on giant salvinia. J. Aquat. Plant Manage. 50:116-124.

Mudge CR, Perret AJ, Winslow JR. 2016. Evaluation of foliar herbicide and surfactant combinations for control of giant salvinia at three application timings. J. Aquat. Plant Manag.e 54:32-36. 
Nelson LS, Glomski LM, Gladwin DN. 2007. Effect of glyphosate rate and spray volume on control of giant salvinia. J. Aquat. Plant Manage. 45:58-61.

Nelson LS, Skogerboe JG, Getsinger KD. 2001. Herbicide evaluation against giant salvinia. J. Aquat. Plant Manage. 39:48-53.

Netherland MD, Richardson RJ. Evaluating sensitivity of five aquatic plants to a novel arylpicolinate herbicide utilizing an organization for economic cooperation and development protocol. Weed Sci. 64:181-190.

Richardson RJ, Haug EJ, Netherland MD. Response of seven aquatic plants to a new arylpicolinate herbicide. 2016. J. Aquat. Plant Manage. 54:26-31.

Shaner, D.L. 2014. Herbicide Handbook. 10th Edition, Weed Science Society of America, Lawrence, 513 p.

Thayer, DD, Pfingsten IA. 2018. Nymphoides cristata (Roxb.) Kuntze: US Geological Survey. Nonindigenous Aquatic Species Database, Gainesville, FL. https://nas.er.usgs.gov/queries $\angle$ FactSheet.aspx?speciesID $=2216$. Accessed September 29, 2020

TRC Environmental. 2017. State of Washington Department of Ecology: Draft supplemental environmental impact statement for state of Washington aquatic plant and algae management. data.wa.gov/views/s55t-vffn/files/5b39oda3-efc8-44a1-86f3-b76b47dab2fd. Accessed September 29, 2020.

University of Florida. 2018. "Details About the Aquatic Herbicides Used in Florida." Plant Management in Florida Waters: An Integrated Approach. http://plants.ifas.ufl.edu/manage/controlmethods/details-about-the-aquatic-herbicides-used-in-florida.

Willey LN. 2012. Biology and Control of the Invasive Aquatic Plant Crested Floating Heart (Nymphoides cristata). M.S. thesis. Gainesville, FL: University of Florida.

Willey LN, Netherland MD, Haller WT, Langeland KA. 2014. Evaluation of aquatic herbicide activity against crested floating heart. J. Aquat. Plant Manage. 52:47-56.

Winslow J. 2013. Amite, Blind, and Tickflow River Complex Vegetation Control Plan. Louisiana Department of Wildlife and Fisheries, Inland Fisheries. 23 pp.

NOTE: The contents of this technical note are not to be used for advertising, publication, or promotional purposes. Citation of trade names does not constitute an official endorsement or approval of the use of such products. 